\title{
Effects of learning experience on forgetting rates of item and associative memories
}

\author{
Jiongjiong Yang, ${ }^{1}$ Lexia Zhan, ${ }^{1}$ Yingying Wang, ${ }^{1}$ Xiaoya Du, ${ }^{1}$ Wenxi Zhou, ${ }^{1}$ \\ Xueling Ning, ${ }^{1}$ Qing Sun, ${ }^{1}$ and Morris Moscovitch ${ }^{2,3}$ \\ ${ }^{1}$ Department of Psychology and Beijing Key Laboratory of Behavior and Mental Health, Peking University, Beijing 100080, \\ China; ${ }^{2}$ Department of Psychology, University of Toronto, Toronto, Ontario M5S 3G3, Canada; ${ }^{3}$ Rotman Research Institute, \\ Baycrest Centre, Toronto, Ontario M6A 2E1, Canada
}

\begin{abstract}
Are associative memories forgotten more quickly than item memories, and does the level of original learning differentially influence forgetting rates? In this study, we addressed these questions by having participants learn single words and word pairs once (Experiment 1), three times (Experiment 2), and six times (Experiment 3) in a massed learning (ML) or a distributed learning $(\mathrm{DL})$ mode. Then they were tested for item and associative recognition separately after four retention intervals: $10 \mathrm{~min}, 1 \mathrm{~d}, 1 \mathrm{wk}$, and $1 \mathrm{mo}$. The contribution of recollection and familiarity processes were assessed by participants' remember/know judgments. The results showed that for both item and associative memories, across different degrees of learning, recollection decreased significantly and was the main source of forgetting over time, whereas familiarity remained relatively stable over time. Learning multiple times led to slower forgetting at shorter intervals, depending on recollection and familiarity processes. Compared with massed learning, distributed learning (six times) especially benefited associative memory by increasing recollection, leading to slower forgetting at longer intervals. This study highlighted the importance of process contribution and learning experiences in modulating the forgetting rates of item and associative memories. We interpret these results within the framework of a dual factor representational model of forgetting (as noted in a previous study) in which recollection is more prone to decay over time than familiarity.
\end{abstract}

According to the contents of the retrieved information, memory can be divided into item memory and associative memory (Murdock 1997; Squire and Wixed 2011). Unlike on tests of item memory, on tests of associative memory, participants have to determine whether the relations between items, or item-context relations, are learned during a study. Establishing and maintaining associations between items is an important aspect of episodic memory. Whether associative memory relies on different mechanisms from item memory remains a central issue of memory research (Murdock 1997; Squire et al. 2004; Davachi 2006). Many studies have suggested that they are dissociated in both behavioral mechanisms and neural substrates, with associative memory relying primarily on recollection and item memory, on familiarity (Gardiner et al. 2002; Cohn and Moscovitch 2007; Eichenbaum et al. 2007). In addition, the hippocampus is critical for and more involved in associative memory than in item memory, whereas the opposite holds for the perirhinal cortex (Davachi 2006; Eichenbaum et al. 2007; but see Squire et al. 2007). Recent evidence, however, suggests that item and associative memory can both depend on recollection and familiarity (Smith et al. 2011), and it is these processes, rather than the types of memory, that determine the neural substrates that are implicated. Less is known, however, about the factors that determine the rate of forgetting for items and associations (e.g., Wixted 1990; Hockley and Consoli 1999; Sadeh et al. 2014). In this paper, we examine the forgetting rate of item and associative memories to ascertain whether recollection and familiarity are determining factors, as they are in retention.

Forgetting is rapid shortly after learning but slows with time (Ebbinghaus 1885/1964). Does this pattern apply to all kinds of

\section{Corresponding author: yangij@pku.edu.cn}

Article is online at http://www.learnmem.org/cgi/doi/10.1101//m.041210.115. memory? Studies have shown that associative memory or source memory declines to a greater extent than item memory (e.g., Brown and Halliday 1991; Sharot and Yonelinas 2008; Talamini and Gorree 2012; Brubaker and Naveh-Benjamin 2014). Remote memories typically are less detailed than recently acquired memories (Moscovitch et al. 2006; Squire and Bayley 2007). For example, in a study by Talamini and Gorree (2012), color pictures and picture-position/picture-picture associations were tested over different retention intervals ( $5 \mathrm{~min}$ to $3 \mathrm{mo}$ ). The results showed that the associative memories decayed faster than memory of single pictures at $1 \mathrm{wk}$ and 1 mo after encoding. However, other behavioral studies have suggested that forgetting rates for item and associative memories are similar over time (at least until 1 wk) (e.g., Bornstein and LeCompte 1995; Hockley and Consoli 1999). For example, Hockley and Consoli (1999) compared memory recognition of words and word pairs over different intervals (30 min versus $1 \mathrm{~d}$ in Experiment $1 ; 2 \mathrm{~d}$ versus $7 \mathrm{~d}$ in Experiment 2), and the results showed that the performance of the two types of memory declined at similar rates.

One way to consider the cause of forgetting is to analyze how the contribution of different processes in item and associative memories change over time. Sadeh et al. (2014) proposed a twofactor, representational theory of forgetting that posits that forgetting depends on how we remember, namely on how items are initially represented in memory. In particular, they based their theory on a proposal by Hardt et al. (2013) that memory relying on the hippocampus is relatively resistant to interference, but

(C) 2016 Yang et al. This article is distributed exclusively by Cold Spring Harbor Laboratory Press for the first 12 months after the full-issue publication date (see http://learnmem.cshlp.org/site/misc/terms.xhtml). After 12 months, it is available under a Creative Commons License (AttributionNonCommercial 4.0 International), as described at http://creativecommons. org/licenses/by-nc/4.0/. 
sensitive to decay. Because recollection relies mainly on the hippocampus and familiarity on extra-hippocampal regions (e.g., Bowles et al. 2007, for review, see Eichenbaum et al. 2007, but see Squire et al. 2007), memories relying on recollection are more sensitive to decay but are relatively resistant to interference from irrelevant information. In contrast, memories relying on familiarity are prone to the detrimental effects of interference but show less effect of decay. Studies using Remember/Know (R/K) and ROC paradigms have found that the proportion of recollection greatly decreases over time, particularly over short intervals, but that of familiarity remains unchanged (Gardiner and Java 1991; Knowlton and Squire 1995; Hockley and Consoli 1999; Barber et al. 2008; Sharot and Yonelinas 2008; Tunney 2010) or even increases (e.g., Viskontas et al. 2009). When the interval is longer than $1 \mathrm{wk}$, the contribution of both processes decreases (Gardiner and Java 1991; Tunney and Bezzina 2007). In a recent test of their theory, Sadeh et al. (2016) found that over intervals of $1 \mathrm{~h}$, memory for words based on recollection is more prone to decay than to interference, whereas the reverse was true of memory based on familiarity.

Neuroimaging studies have also shown that the decrease of hippocampus activity is associated with recollection decline (e.g., Viskontas et al. 2009; Harand et al. 2012). Patients with hippocampal lesions have more rapid forgetting of recollection-based memory for recent events (for review, see Sadeh et al. 2014). Because the hippocampus is crucial in processing detailed or contextual information (for review, see Davachi 2006; Mayes et al. 2007) even after a long time (Gilboa et al. 2004, Moscovitch et al. 2006), the recollection change may reflect the extent to which detailed information is forgotten over time. Based on the above findings and assumptions, we adopt the same approach to reexamine the forgetting mechanisms of item and associative memories. As item and associative memories both depend on recollection and familiarity (Smith et al. 2011), but possibly to a different extent, it is possible that their forgetting rate may be comparable or different, according to what extent to item and associative memories relies on the two processes over time.

In addition, most of the above studies present stimuli only once during learning. The forgetting rate may be modulated by degree of learning and spacing effect. Early studies have shown that repetition of learning produces slower forgetting (Ebbinghaus 1885/1964; Loftus 1985), but others have argued that learning does not influence the forgetting rate (e.g., Slamecka and McElree 1983; Slamecka 1985; Nilsson et al. 1989; Bogartz 1990; for review, see Wixted 1990). For example, after participants learned words (Experiment 1) and word pairs (Experiment 2) once or three times, they were tested immediately, 1 and $5 \mathrm{~d}$ later by recalling the categorical words or pairs, or recognizing word pairs (Slamecka and McElree 1983). The results showed that for each memory type, there was no significant interaction between learning and retention interval-although the intercept of forgetting curves increased, the slope remained stable. Note that the time interval was within $1 \mathrm{wk}$ in this study, and comparison of time interval was between participants. In addition, multiple learning may boost recollection/familiarity process or both processes. If the two processes differ in their decay rate, it is important to clarify whether the learning experience influences recollection and familiarity processes, and if so, how forgetting rates change for item and associative information.

Furthermore, distributed learning (DL) usually leads to better memory performance than massed learning (ML) (i.e., spacing effect. For review, see Janiszewski et al. 2003; Cepeda et al. 2006), and may have different effects on forgetting of item and associative memories. In a study of Litman and Davachi (2008), participants learned word pairs twice in $2 \mathrm{~d}$ (i.e., DL), twice within $1 \mathrm{~d}$ (i.e., ML) and once within $1 \mathrm{~d}$, and then they were tested by recall and recognition after 10-min and 1-d intervals. The results showed that for associative memory, the DL performance was better than that of ML at the 1-d interval, but this pattern did not apply to item memory. It suggested that DL decreases the forgetting rate of associative memory at the 1-d interval. Other studies have found that DL enhances the performance speed rather than accuracy when face-location associations are learned using DL (versus ML) (e.g., Takashima et al. 2007).

On the other hand, the cognitive mechanism of spacing effect is not quite clear, mostly emphasizing the role of encoding variability and consolidation (Janiszewski et al. 2003; Cepeda et al. 2006), but there is a lack of empirical evidence on this matter. As for the underlying processes, consider that after participants learned the stimuli by DL, compared with ML, they could obtain more contextual information about the stimuli. This could lead to more contribution of the recollection process. If forgetting rate is more related to recollection contribution, then DL experience may slow memory decay. Recent studies shed light on this assumption. For example, Vilberg and Davachi (2013) showed that after DL rather than ML mode, the connectivity between hippocampus and perirhinal cortex was correlated with decreased forgetting of object-based associative memory. It is worthwhile, therefore, to explore the outcome of spacing effect over time to clarify whether the spacing effect lasts for a longer interval than $1 \mathrm{~d}$.

In sum, the questions addressed in this study were: (1) whether associative memory decays more quickly than item memory, and whether the decay of two types of memory relies on different processes (i.e., recollection and familiarity). (2) Whether learning repetition modulates the decay of recollection and familiarity in item and associative memories. (3) Whether different modes of learning (ML versus DL) modulates the decay of recollection and familiarity in item and associative memories.

Participants were asked to study single words and word pairs in each experiment. To ensure that words and word pairs were both encoded, participants performed a concreteness judgment for each word, and a relational task (e.g., make a sentence) for each word pair. To determine the effect of learning on memory performance, participants were asked to learn words and word pairs once (Experiment 1), three times in ML or DL mode (Experiment 2), and six times in ML or DL mode (Experiment 3). During retrieval, participants performed recognition tasks at different time intervals after the last learning trial (i.e., $10 \mathrm{~min}, 1 \mathrm{~d}$, $1 \mathrm{wk}$, and $1 \mathrm{mo}$ ). At each time interval, they were asked to make old/new judgment for item recognition, and old/recombined judgment for associative recognition. For either item or associative recognition task, participants further made remember/ know/guess judgments for their responses to dissociate recollection and familiarity processes. The forgetting rate of each condition was analyzed and compared in each experiment. As forgetting typically involves losing detailed or contextual information (Winocur and Moscovitch 2011), we hypothesized that across three experiments, memory relying on recollection, rather than familiarity, would be more sensitive to decay (Sadeh et al. 2014). As both recollection and familiarity processes contribute to associative and item memory, the difference in forgetting rate between the two memory types after learning once should be minimal. Repetition learning slows down the forgetting rate by increasing the contribution of recollection. Compared with massed learning, distributed learning increases contextual information during encoding (Glenberg, 1979; Janiszewski et al. 2003; Cepeda et al. 2006) and reactivation process to consolidate associations between words. Accordingly, the forgetting rate of associative memory, rather than item memory, would be decreased. 


\section{Results}

\section{Experiment 1}

In Experiment 1, participants were presented word pairs once during learning, then they judged old/new words and old/recombined word pairs during retrieval after 10-min, 1-d, 1-wk, and 1-mo intervals. The corrected recognition (Hit-FA), Hit rate, FA rate, RTs, and contribution of recollection and familiarity were analyzed separately using a repeated-measures ANOVA with the time interval (10 $\mathrm{min}, 1 \mathrm{~d}, 1 \mathrm{wk}, 1 \mathrm{mo}$ ) and the memory type (item, associative) as within-subjects factors.

\section{Results}

The results of corrected recognition showed that memory performance decreased over time $\left(F_{(3,66)}=73.11, P<0.001, \eta^{2}=0.75\right)$. For both item and associative memory tests, recognition performance decreased from $10 \mathrm{~min}$ to $1 \mathrm{~d}(P<0.001), 1 \mathrm{~d}$ to $1 \mathrm{wk}$ $(P=0.08)$, and from $1 \mathrm{wk}$ to $1 \mathrm{mo}(P=0.05)$ (Fig. $1 \mathrm{~A})$. There was no significant interaction between retention interval and memory type $\left(F_{(3,66)}=0.39, P=0.76, \eta^{2}=0.02\right)$. Item and associative memory performance were comparable $\left(F_{(1,22)}=2.59, P=\right.$ $\left.0.12, \eta^{2}=0.17\right)$. The values of Hit-FA in different conditions were significantly higher than expected by chance $(0)(P \mathrm{~s}<$ $0.05)$, except in the case of 1 -mo associative memory $\left(t_{(22)}=\right.$ $0.38, P=0.34)$. The response bias did not show significant effects of time and memory type, nor interaction of time and memory type $(F s<1)$.

Similar to the corrected recognition, the Hit rate decreased over time $\left(F_{(3,66)}=57.08, P<0.001, \eta^{2}=0.63\right)$ (Fig. 1B). Here, the interaction between memory type and time interval was significant $\left(F_{(3,66)}=6.61, P=0.001, \eta^{2}=0.20\right)$, showing that the higher Hit rate for item (versus associative) memory was obvious for 1-wk and 1-mo intervals (longer intervals, $P$ s $<0.001$ ) but not for 10-min and 1-d intervals (shorter intervals, Ps $>0.55$ ).
In addition, the Hit rate of item memory remained stable from 1 $\mathrm{d}$ to $1 \mathrm{wk}(P=1.0)$, whereas that of associative memory was stable from 1 -wk to 1 -mo interval $(P=0.48)$. For the FA rate, there was significant effect of time interval $\left(F_{(3,66)}=8.33, P=0.001, \eta^{2}=\right.$ $0.32)$, increasing from $10 \mathrm{~min}$ to $1 \mathrm{~d}(P<0.001)$ and remained stable thereafter $(P s=1.0)$. For the RTs, participants performed more slowly on tests of associative memory than on tests of item memory $\left(F_{(1,22)}=614.68, P<0.001, \eta^{2}=0.96\right)$ because they had to judge the relationship between the two words (Table 1 ). There was no significant effect of time interval, nor was the interaction between memory type and interval $(F<1)$. The interaction and memory type effect were not significant (Ps $>0.20)$.

Because familiarity and recollection can contribute to both item and associative memory, we examined how they were affected by our manipulations. Similar repeated-measures ANOVA tests were performed separately for recollection and familiarity processes. Regarding the contribution of recollection, there was a significant effect of time interval $\left(F_{(3,66)}=99.81, P<0.001, \eta^{2}=\right.$ 0.82 ) and significant interaction between time interval and memory type $\left(F_{(3,66)}=8.96, P<0.001, \eta^{2}=0.29\right)$, suggesting different decay patterns for item and associative memories that are recollected. Further analysis showed that the recollection estimates became less over time for associative memory from $10 \mathrm{~min}$ to 1 mo, and for item memory from $10 \mathrm{~min}$ to $1 \mathrm{~d}$ and remained stable afterward. In addition, recollection was higher for associative memory than for item memory at the 10-min and 1-d intervals $(P \mathrm{~s}<0.05)$ but not at longer intervals $(P \mathrm{~s}>0.05)$ (Fig. 1C).

Regarding the contribution of familiarity, there was a significant effect of time interval $\left(F_{(3,66)}=4.04, P=0.011, \eta^{2}=0.16\right)$, but further pairwise comparisons did not show significant differences between any two time intervals $(P s>0.10)$. The interaction of time and memory type was not significant $\left(F_{(3,66)}=1.49\right.$, $P=0.23, \eta^{2}=0.06$ ). This suggested that familiarity processes operate similarly over time for both item and associative memories. When contribution of recollection and familiarity was directly
A

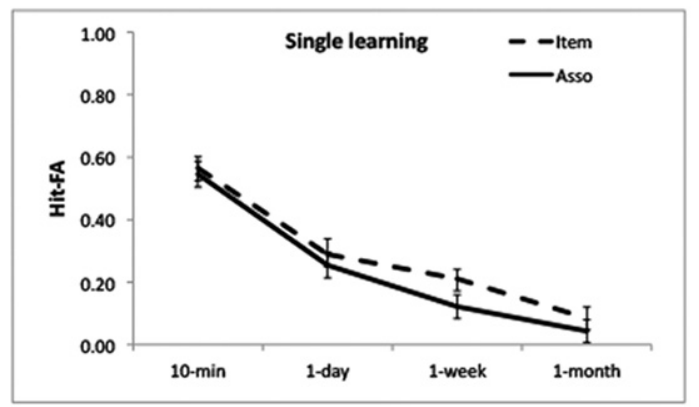

B

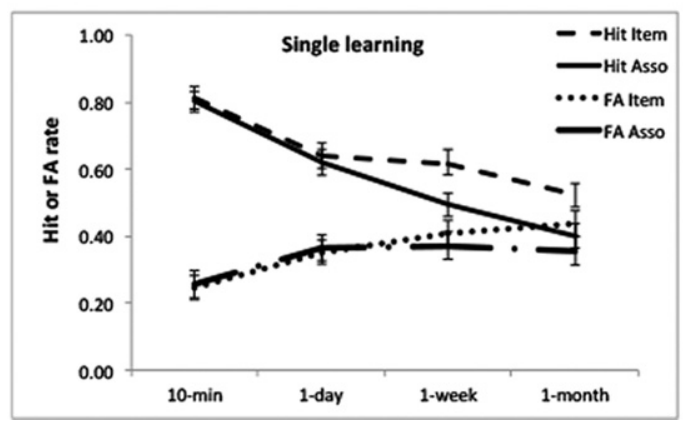

C

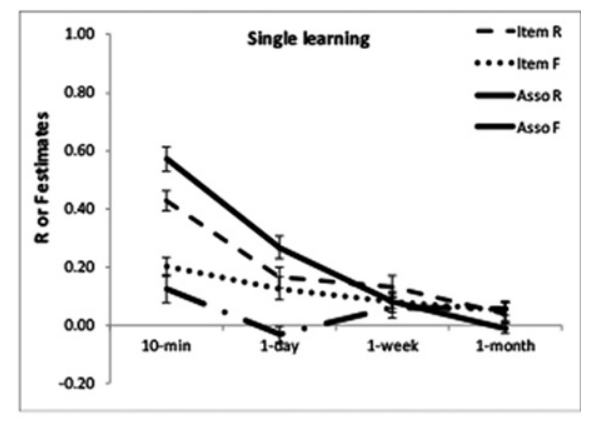

Figure 1. Results of Experiment 1. $(A)$ Corrected recognition. $(B)$ Hit and FA rates. $(C)$ Contribution of recollection and familiarity. The error bars represent the standard errors of the means. 
Table 1. RTs in Experiment 1-3 (msec)

\begin{tabular}{|c|c|c|c|c|c|c|c|c|c|}
\hline & & \multicolumn{2}{|c|}{$10 \mathrm{~min}$} & \multicolumn{2}{|c|}{$1 \mathrm{~d}$} & \multicolumn{2}{|c|}{$1 \mathrm{wk}$} & \multicolumn{2}{|c|}{$1 \mathrm{mo}$} \\
\hline & & Item & Asso & Item & Asso & Item & Asso & Item & Asso \\
\hline \multirow[t]{2}{*}{ Once } & Mean & 1023 & 1461 & 1043 & 1420 & 1023 & 1346 & 1017 & 1325 \\
\hline & SD & 87 & 220 & 107 & 217 & 129 & 249 & 133 & 267 \\
\hline \multirow[t]{2}{*}{ ML3 } & Mean & 880 & 1194 & 888 & 1202 & 943 & 1220 & 946 & 1217 \\
\hline & SD & 111 & 181 & 131 & 205 & 128 & 183 & 124 & 219 \\
\hline \multirow[t]{2}{*}{ DL3 } & Mean & 871 & 1123 & 910 & 1164 & 987 & 1229 & 991 & 1242 \\
\hline & SD & 112 & 226 & 133 & 208 & 146 & 180 & 138 & 220 \\
\hline \multirow[t]{2}{*}{ ML6 } & Mean & 968 & 1250 & 979 & 1194 & 1045 & 1358 & 983 & 1258 \\
\hline & SD & 99 & 141 & 105 & 161 & 125 & 166 & 111 & 178 \\
\hline \multirow[t]{2}{*}{ DL6 } & Mean & 885 & 1079 & 905 & 1161 & 997 & 1236 & 1006 & 1295 \\
\hline & SD & 106 & 156 & 125 & 196 & 163 & 202 & 131 & 193 \\
\hline
\end{tabular}

compared, the results showed that there was greater recollection than familiarity for associative memory at 10 -min and 1-d intervals ( $P \mathrm{~s}<0.001)$, and for item memory at 10 -min interval $(P=0.047)$. It suggested that both associative and item memories rely on both processes over longer intervals. The estimates of familiarity for associative memory were above chance level except for 1-d interval $(P s>0.10)$. Note that the estimate of recollection was at chance level at 1 -mo interval $(P=0.60)$.

The averaged guess responses were $0.16 \pm 0.07$ for the raw data, and $0.00 \pm 0.05$ after correction by the FA rate. They were not significantly different from chance level for each condition $(P s>0.15)$. There were no significant effects of time and memory type, or significant interactions between time and memory type for the guess responses ( $F \mathrm{~s}<3, P>0.10)$.

\section{Summary and comment}

The main result of Experiment 1 was that the interaction between memory type and retention interval was not significant for corrected recognition. Although the memory performance decreased quickly from 10 min to $1 \mathrm{~d}$, which was consistent with Ebbinghaus's (1886) forgetting curve, the results of corrected recognition showed that item and associative memories had similar forgetting rates. The result supported the finding of Hockley and Consoli (1999) and further extended the time interval to 1 mo.

More important, the contribution of recollection decreased significantly over time, whereas that of familiarity did not. Recollection decreased mainly from $10 \mathrm{~min}$ to $1 \mathrm{~d}$ for item memory and linearly from $10 \mathrm{~min}$ to $1 \mathrm{mo}$ for associative memory. It suggested that the decline in recollection process, which contributes to both item and associative memory, is the main cause of forgetting over time (Sadeh et al. 2014). It is important to note, however, that the experiment was not designed to examine the effects of interference on forgetting where familiarity is expected to be more vulnerable, as shown in a recent study by Sadeh et al. (2016).

Note that at the 1-d interval, associative memory was more dependent on recollection, but item memory was dependent on both recollection and familiarity. This pattern was consistent with previous findings on dissociation of item and associative memory (Eichenbaum et al. 2007). One reason for the equivalent rates is that recollection may have converted to familiarity but it is unlikely that the reverse occurred. In general, however, as both item and associative memory depend on recollection and familiarity, the difference between them in forgetting rate was minimal.

\section{Experiment 2}

In Experiment 2, participants learned the words and word pairs three times within $1 \mathrm{~d}$ in the ML group, whereas participants learned the material once per day for $3 \mathrm{~d}$ in DL group. The estimates of recollection and familiarity were also adopted to explore whether the same pattern we found in Experiment 1 for single learning trials applies to multiple learning trials that are either massed or distributed.

\section{Massed learning (ML3)}

The results of corrected recognition showed that memory performance decreased over time from $10 \mathrm{~min}$ to $1 \mathrm{mo}\left(F_{(3,81)}=93.09\right.$, $\left.P<0.001, \eta^{2}=0.77\right)$. Unlike Experiment 1 , there was significant interaction between time interval and memory type $\left(F_{(3,81)}=\right.$ 7.84, $P<0.001, \eta^{2}=0.24$ ) (Fig. 2 A). The result reflected the fact that item memory decreased more rapidly from 10 min to $1 \mathrm{~d}$ than associative memory. Item memory was better than associative memory at the 10 -min interval $(P=0.004)$ but comparable at other intervals $(P s>0.10)$. The values of Hit-FA in different conditions were significantly higher than expected by chance $(P s<0.01)$. The response bias did not show significant effects, or interaction of time and memory type $(F \mathrm{~s}<2)$.

The Hit rate decreased over time $\left(F_{(3,81)}=84.87, P<0.001\right.$, $\left.\eta^{2}=0.76\right)$. The interaction between memory type and interval was not significant $\left(F_{(3,81)}=1.36, P=0.26, \eta^{2}=0.05\right)$, and the Hit rate was comparable for the two memory types $\left(F_{(1,27)}=\right.$ $2.67, P=0.14, \eta^{2}=0.09$ ) (Fig. 2B). For the FA rate, there was a significant interaction $\left(F_{(3,81)}=20.40, P<0.001, \eta^{2}=0.43\right)$ because the FA rate remained stable across time for associative memory (Ps $>0.80)$, but increased over time for item memory from $1 \mathrm{~d}$ to $1 \mathrm{mo}(P \mathrm{~s}<0.05)$. Accordingly, the FA rate was significantly higher for item memory than for associative memory at 1-wk and 1-mo intervals $(P s<0.05)$. For the RTs, participants performed more slowly on tests of associative than of item memory $\left(F_{(1,27)}=269.9, P<0.001, \eta^{2}=0.91\right)$, but there was no significant effect of time interval, nor was the interaction between memory type and interval $(F<1)$.

Regarding the contribution of recollection, there was a significant interaction between memory type and time interval $\left(F_{(3,81)}=2.94, P=0.04, \eta^{2}=0.10\right)$. The recollection estimates decreased from $10 \mathrm{~min}$ to $1 \mathrm{mo}$ for both memory types $\left(F_{(3,81)}=\right.$ 149.02, $\left.P<0.001, \eta^{2}=0.85\right)$, and recollection contributed similarly to associative and item memories except at the 1-wk interval $(P=0.025)$ (Fig. 2C). This result suggested that recollection of associative memory decreases more slowly from $1 \mathrm{~d}$ to $1 \mathrm{wk}$ than that of item memory. For familiarity, there was no significant difference between time intervals $(P \mathrm{~s}>0.05)$. The significant interaction $\left(F_{(3,81)}=4.51, P=0.009, \eta^{2}=0.13\right)$ indicated that familiarity was contributing more to item than associative memory from 10 -min to 1 -wk intervals $(P \mathrm{~s}<0.02)$ but not at the 1-mo interval $(P=0.93)$ (Fig. $2 \mathrm{~B})$. The estimates of familiarity for associative memory were above chance level at 1-wk and 
A

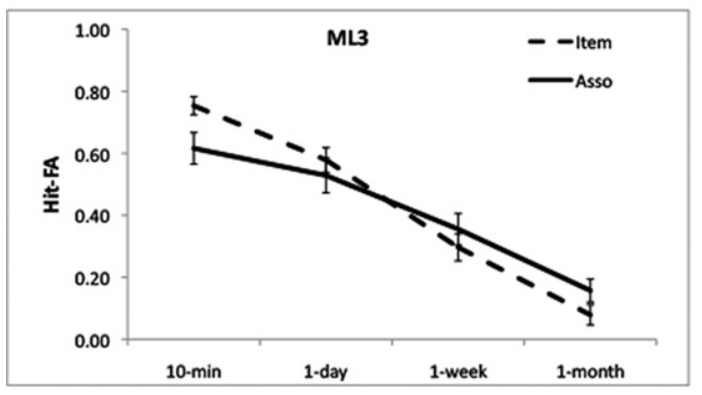

B

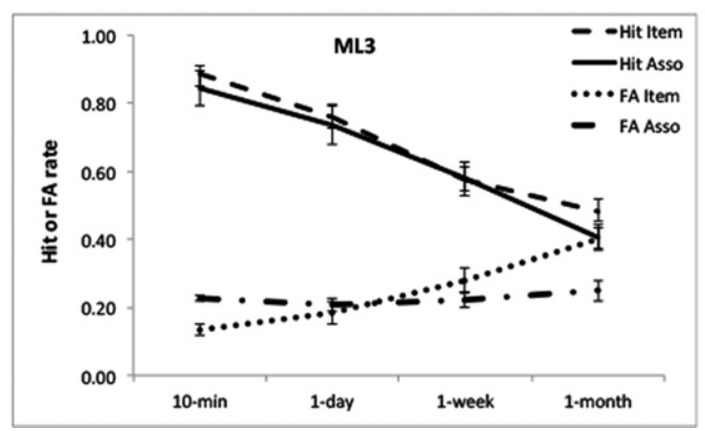

C

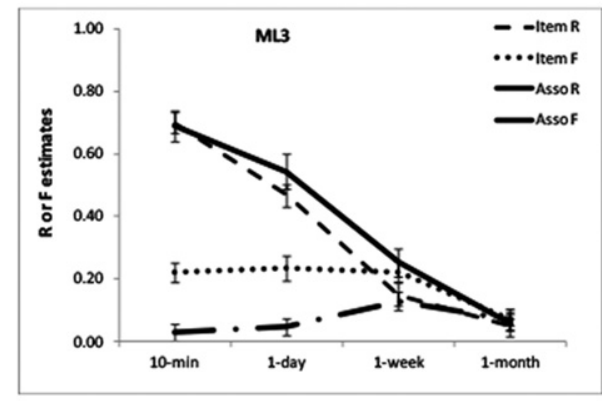

Figure 2. Results of ML3 in Experiment 2. (A) Corrected recognition. (B) Hit and FA rates. (C) Contribution of recollection and familiarity. The error bars represent the standard errors of the means.

1-mo intervals $(P s<0.02)$, but not at 20 -min and 1-d intervals $(P \mathrm{~s}>0.10)$. To compare recollection and familiarity, there was more contribution of recollection than that of familiarity for item memory at 10 -min and 1 -d intervals $(P<0.001)$, and for associative memory at 10 -min to 1 -wk intervals $\left(P_{\mathrm{s}}<0.01\right)$. The averaged guess responses $0.00 \pm 0.05$ after correction by the FA rate. They were not significantly different from the chance level (0) for each condition ( $P S>0.10$ ) except for the associative memory at 1 -mo interval $(P=0.02)$. There was significant interaction of time and memory type $\left(F_{(3,81)}=4.10, P=0.01, \eta^{2}=0.13\right)$, which showed that there were more guess responses for associative than item memory at 1 -mo interval $(P=0.02)$, but was comparable at other intervals $(P \mathrm{~s}>0.10)$.

\section{Distributed learning (DL3)}

For corrected recognition, memory performance decreased over time $\left(F_{(3,72)}=101.16, P<0.001, \eta^{2}=0.81\right)$ (Fig. 3A). Similar to that in ML3 group, there were marginal significant effects of interaction $\left(F_{(3,72)}=2.40, P=0.076, \eta^{2}=0.09\right)$. Further comparison showed that associative memory decreased from 1-d to 1-mo $(P s<0.05)$, whereas item memory decreased from 10 min to 1 mo $(P s<0.05)$. Item memory was better than associative memory at the 10-min interval $(P=0.05)$ but comparable at other intervals $(P s>0.10)$. The response bias did not show significant effects, or interaction of time and memory type $(F s<2)$.

The Hit rate decreased over time $\left(F_{(3,72)}=55.29, P<0.001\right.$, $\left.\eta^{2}=0.70\right)$, but the interaction between memory type and interval was not significant, nor was the effect of memory type ( $F \mathrm{~s}<1$, $P>0.40$ ) (Fig. 3B). For the FA rate, there was a significant interaction between retention interval and memory type $\left(F_{(3,72)}=3.01\right.$, $\left.P=0.04, \eta^{2}=0.11\right)$. This occurred because the FA rate increased from $1 \mathrm{wk}$ for item memory $(P<0.001)$ but remained stable for associative memory $(P s>0.20)$. There were no significant effects for the RTs $(F \mathrm{~s}<1)$.
Regarding the contribution of recollection, there was a significant interaction between time interval and memory type $\left(F_{(3,72)}=2.93, P<0.039, \eta^{2}=0.11\right)$. As shown in ML3 group, recollection decreased over time from $10 \mathrm{~min}$ to $1 \mathrm{mo}\left(F_{(3,72)}=\right.$ 189.83, $\left.P<0.001, \eta^{2}=0.89\right)$ for both memory types, but there was greater recollection of associative than item memory at 1-d and 1-wk intervals ( $P \mathrm{~s}<0.01)$ (Fig. 3C). This finding suggested that recollection decreased more slowly for associative than for item memory at shorter intervals. For the contribution of familiarity, the main effect of time interval was significant $\left(F_{(3,72)}=7.03\right.$, $P<0.001, \eta^{2}=0.23$ ), but further analysis showed that there was no significant difference between time intervals ( $P S>0.05)$. The significant interaction $\left(F_{(3,72)}=2.61, P=0.066, \eta^{2}=0.10\right)$ indicated that familiarity contributed more to item than associative memory at the 10 -min to 1 -wk intervals $(P \mathrm{~s}<0.05)$ but not for 1 -mo $(P=0.11)$. The contribution of recollection was greater than that of familiarity for item memory at 10-min and 1-d intervals $(P<0.001)$, and for associative memory at $10 \mathrm{~min}$ until $1 \mathrm{wk}$ $(P s<0.01)$. The averaged guess response was $0.01 \pm 0.05$ after correction by the FA rate. They were not significantly higher than the chance level $(0)$ for each condition $(P s>0.10)$. There were no significant effects of time and memory type, or significant interaction between them $(F \mathrm{~s}<3, P>0.10)$.

\section{Group or spacing effect (ML3 versus DL3)}

To explore the spacing effect on the forgetting rate, an additional ANOVA was performed with group (ML3 versus DL3) as a betweensubjects factor. Spaced learning significantly increased corrected recognition $\left(F_{(1,51)}=5.03, P=0.03, \eta^{2}=0.09\right)$, but the interactions related to group, including the interaction between time interval and group, were not significant $(P S>0.28)$. It suggested that spacing does not influence the forgetting rate. There was a main effect of contribution of recollection, greater for DL3 than ML3 $\left(F_{(1,51)}=6.70, P=0.01, \eta^{2}=0.12\right)$. For the contribution of 
A

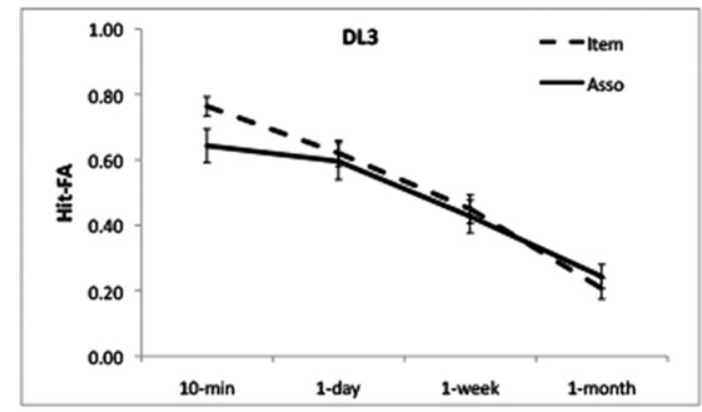

B

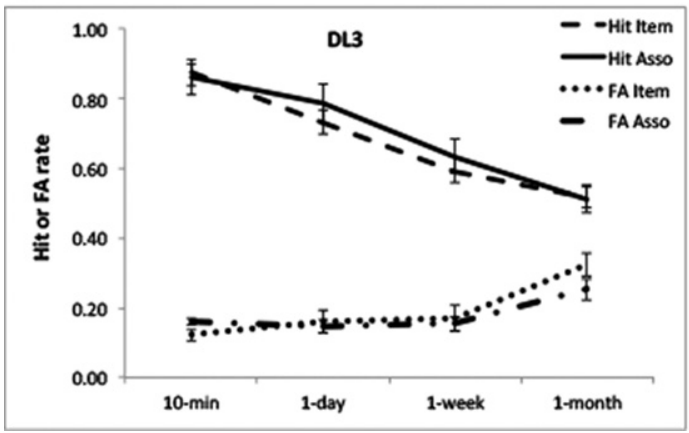

C

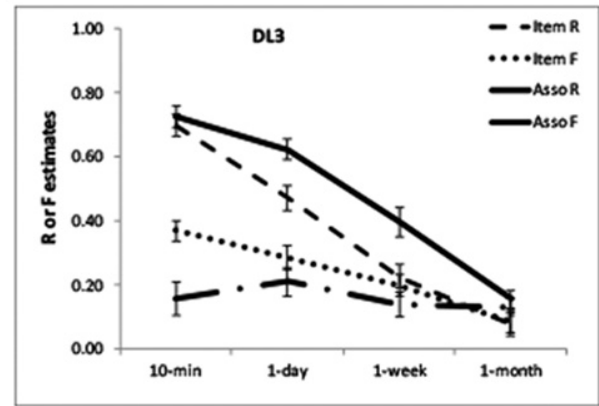

Figure 3. Results of DL3 in Experiment 2. (A) Corrected recognition. (B) Hit and FA rates. (C) Contribution of recollection and familiarity. The error bars represent the standard errors of the means.

familiarity, there was significant time by group interaction $\left(F_{(1,153)}=5.30, P=0.02, \eta^{2}=0.09\right)$, because there was more contribution of familiarity for DL3 versus ML3 at 1-mo interval $(P<0.001)$ but not at other intervals $(P s>0.28)$. In summary, DL3 increased general memory performance over ML3, increased the contribution of recollection at all intervals, but familiarity only at longer intervals. The forgetting rate did not differ between DL3 and ML3.

\section{Learning effect (Experiment 1 versus ML3 in Experiment 2)}

To explore the effect of learning time on the forgetting rate, another ANOVA was performed with learning (once versus ML3) as a between-subjects factor. The results showed a significant learning effect $\left(F_{(1,49)}=17.67, P<0.001, \eta^{2}=0.27\right)$. There were also significant interactions between time interval and learning $\left(F_{(3,147)}=6.80, P<0.001, \eta^{2}=0.12\right)$ and among time, learning, and memory type $\left(F_{(3,147)}=4.42, P=0.005, \eta^{2}=0.08\right)$. The learning effect was significant at the 10-min and 1-d intervals for item memory (Ps < 0.001) and significant from 1-d to 1-mo intervals for associative memory $(P s<0.05)$. After learning three times, item memory decreased less from $1 \mathrm{~d}$ to $1 \mathrm{wk}$, and associative memory decreased less from $10 \mathrm{~min}$ to $1 \mathrm{~d}$. The results suggested that learning three times leads to slower forgetting rate at shorter intervals.

The result of recollection was similar to that of corrected recognition. There was more contribution of recollection for ML3 than for once $\left(F_{(1,49)}=16.76, P<0.001, \eta^{2}=0.26\right)$. There were significant interactions between interval and learning $\left(F_{(3,147)}=\right.$ 12.04, $\left.P<0.001, \eta^{2}=0.18\right)$ and among time, learning, and memory type $\left(F_{(3,147)}=7.70, P<0.001, \eta^{2}=0.14\right)$. The learning effect appeared at all-time intervals for associative memory and for item memory at 10 -min and 1 -d intervals (Ps $<0.01$ ). For familiarity, there was also a significant interaction between interval and learning $\left(F_{(3,147)}=3.69, P=0.01, \eta^{2}=0.07\right)$, showing more contribu- tion of familiarity at 1-d and 1-wk intervals for ML3 (versus once). These findings suggested that learning more times increases both recollection and familiarity.

\section{Summary and comment}

The result of Experiment 2 showed that for both ML3 and DL3, associative memory decreased more slowly than item memory from 10-min to 1-d. The contribution of recollection decreased significantly over time, whereas that of familiarity did not. Recollection decreased more slowly for associative memory than item memory at shorter intervals for both ML3 and DL3 groups.

Compared with learning once, learning three times significantly increased both item and associative memories at shorter intervals. In addition, learning slowed down the forgetting rate in shorter intervals especially for associative memory. Both recollection and familiarity contributed to the learning effects. Note that although familiarity increased with learning at 1-d and 1-wk intervals, there was no significant decrease over time, suggesting that change in recollection mainly accounts for the forgetting rate. Although memory performance was generally better for DL3 than for ML3, the forgetting rate was equivalent across memory type and memory process.

\section{Experiment 3}

In Experiment 2, we did not find significant spacing effect on the forgetting rate. The results did not conform to our hypothesis of enhanced effect for associative memory. It was also different from that of a previous study of Litman and Davachi (2008), which showed that associative memory benefited more from DL at 1-d interval than from ML. We considered one of the reasons was that the number of times the participants learned each day was not enough. It is possible that more learning sessions per day is necessary for enhanced spacing effect. Therefore, in Experiment 3, to further explore the spacing effect on item and 
associative memories, we asked participants to learn single words and word pairs for six times instead of three times. In DL6 group, participants learned stimuli twice within a day for $3 \mathrm{~d}$, whereas in ML group, participants learned stimuli six times within a day.

\section{Massed learning (ML6)}

The corrected recognition decreased over time $\left(F_{(3,69)}=137.61\right.$, $\left.P<0.001, \eta^{2}=0.86\right)$. There was no significant interaction between time interval and memory type $\left(F_{(3,69)}=2.03, P=0.11\right.$, $\left.\eta^{2}=0.09\right)$. On both item and associative memory tests, recognition performance was stable from 10-min to 1-d interval $(P=0.57)$, but the performance decreased afterward $(P \mathrm{~s}<0.001)$ (Fig. 4A). The memory performance of item and associative memories was comparable $\left(F_{(1,23)}=2.70, P=0.11, \eta^{2}=0.11\right)$. The values of Hit-FA in different conditions were significantly higher than expected by chance $(P s<0.05)$. The response bias did not show significant effects, or interaction of time and memory type $(F \mathrm{~s}<2)$.

Similar to the corrected recognition, the Hit rate decreased over time $\left(F_{(3,69)}=46.04, P<0.001, \eta^{2}=0.63\right)$, and the Hit rate for associative memory was comparable to that for item memory $\left(F_{(1,23)}=0.023, P=0.88, \eta^{2}=0.01\right)$ (Fig. 4B). The interaction between them was not significant $\left(F_{(3,69)}=1.20, P=0.32, \eta^{2}=\right.$ $0.05)$. For the FA rate, there was a significant interaction between retention interval and memory type $\left(F_{(3,69)}=8.53, P<0.001\right.$, $\eta^{2}=0.27$ ) because the FA rate remained stable across time for associative memory ( $P s>0.15)$, but increased over time for item memory from $1 \mathrm{~d}$ to $1 \mathrm{mo}(P \mathrm{~s}<0.02)$. Accordingly, the FA rate was significantly higher for item memory than for associative memory in 1 -wk and 1 -mo intervals $(P s<0.05)$. RTs on associative memory was slower than that on item memory $\left(F_{(1,23)}=240.31\right.$, $\left.P<0.001, \eta^{2}=0.91\right)$. Although the interaction was significant $\left(F_{(3,69)}=3.17, P=0.03, \eta^{2}=0.12\right)$, further analysis showed no significant effects in time two-way comparisons ( $P \mathrm{~s}>0.10)$.
Regarding the contribution of recollection, there was a marginally significant interaction between memory type and retention interval $\left(F_{(3,69)}=2.52, \quad P=0.07, \quad \eta^{2}=0.11\right)$. The recollection estimates remained stable from 10-min to 1-d interval for both memory types (Fig. 4C), then it decreased from 1-d to 1 -wk interval for item memory, and decreased linearly from 1-d to 1-mo for associative memory. The result was consistent with that of the corrected recognition. Recollection estimate was larger for associative than item memory at 1 -d $(P=0.05)$ and 1 -wk $(P<$ $0.001)$ intervals. For familiarity, there were no significant effects of the retention interval, the test and the interaction between them (Fs $<4.0, P \mathrm{~s}>0.05$ ). Recollection contributed more than familiarity over the various retention intervals $(P<0.001)$ except for the 1-mo interval $(P=0.92)$. The averaged guess response was $0.00 \pm 0.04$ after correction by the FA rate. They were not significantly higher than the chance level (0) for each condition (Ps > 0.20 ). There were no significant effects of time and memory type, or significant interaction between them $(F \mathrm{~s}<3, P>0.10)$.

\section{Distributed learning (DL6)}

The corrected recognition decreased over time $\left(F_{(3,63)}=51.16\right.$, $\left.P<0.001, \eta^{2}=0.71\right)$. There was a significant interaction between retention interval and memory type $\left(F_{(3,63)}=3.60, P=0.018\right.$, $\left.\eta^{2}=0.15\right)$, showing that associative memory was better than item memory for different intervals $(P s<0.01)$ except for the 10 -min interval $(P=1.0)$. In addition, for associative memory, a significant decrease only occurred between 1 wk and 1 mo $(P<$ $0.001)$, but for item memory, recognition performance decreased linearly from $1 \mathrm{~d}$ to $1 \mathrm{mo}(P \mathrm{~s}<0.01)$ (Fig. 5A). This result suggested that DL6 significantly decrease the forgetting rate for associative (versus item) memory. The values of Hit-FA in different conditions were significantly higher than expected by chance $(P s<0.05)$. The response bias did not show significant effects, or interaction of time and memory type $(F s<2)$.
A

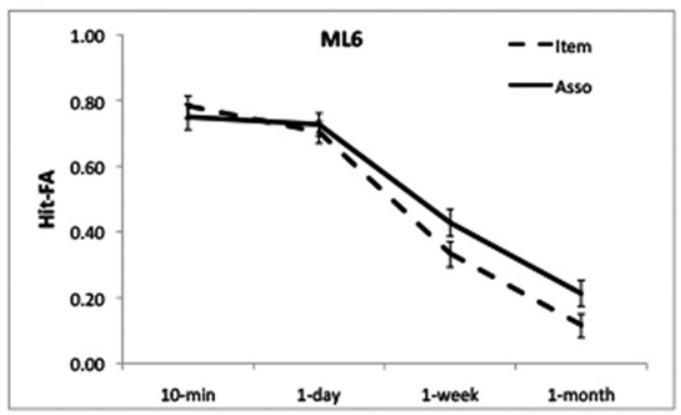

B

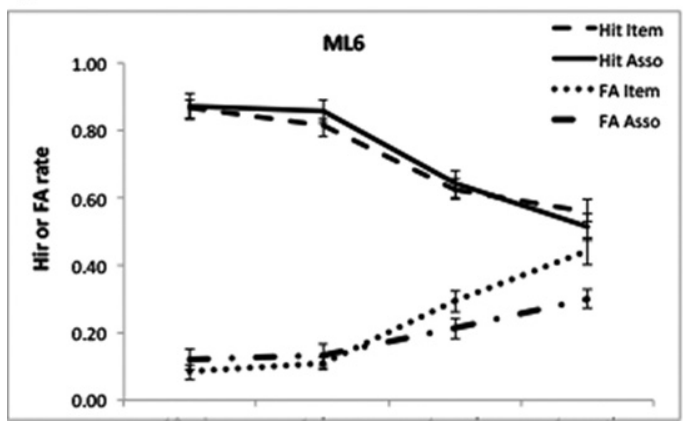

C

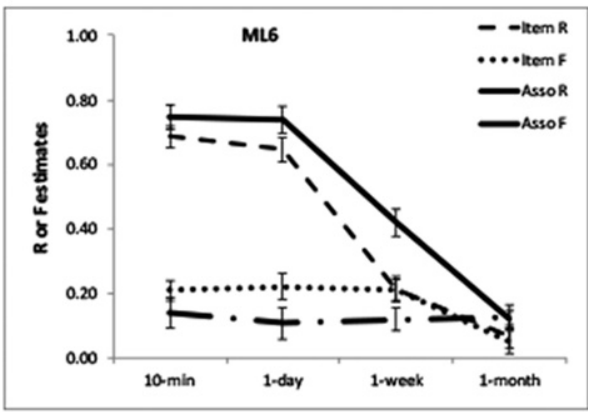


A

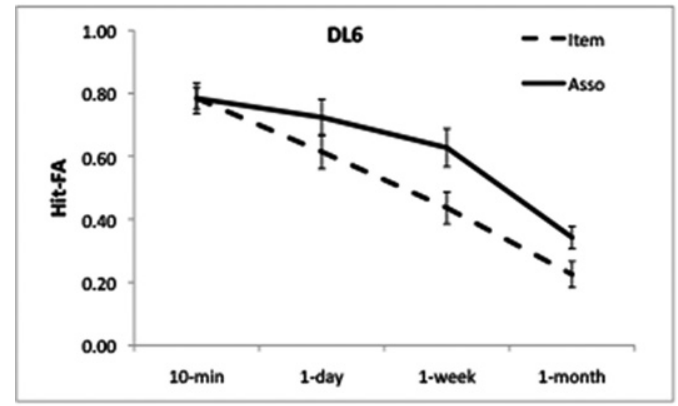

B

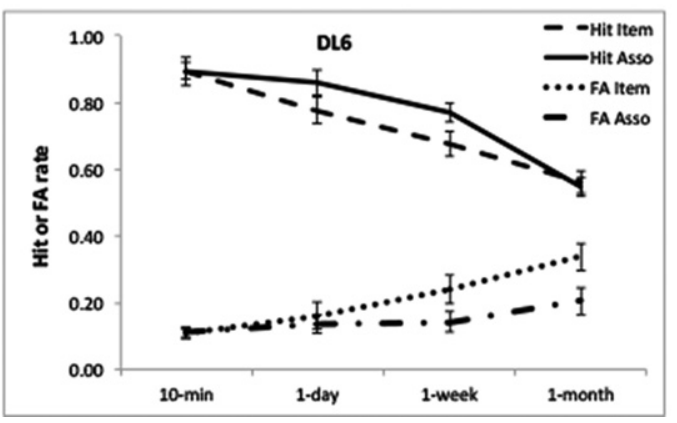

C

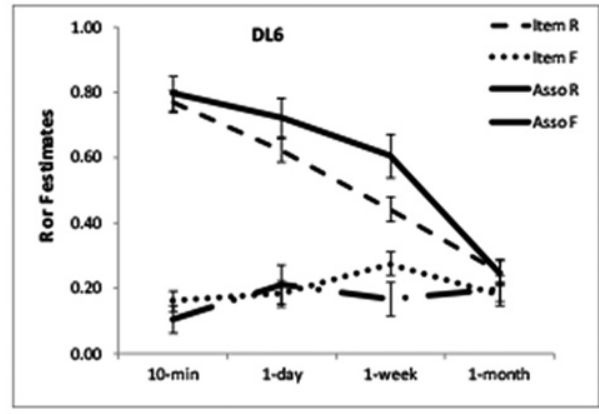

Figure 5. Results of DL6 in Experiment 3. (A) Corrected recognition. (B) Hit and FA rates. (C) Contribution of recollection and familiarity. The error bars represent the standard errors of the means.

The Hit rate decreased over time $\left(F_{(3,63)}=39.18, P<0.001\right.$, $\left.\eta^{2}=0.65\right)$, and the interaction between them was significant $\left(F_{(3,63)}=3.69, P=0.02, \eta^{2}=0.15\right)$. The pattern was the same as that of the corrected recognition (Fig. 5B). For the FA rate, there was a significant interaction between retention interval and memory type $\left(F_{(3,63)}=3.94, P<0.01, \eta^{2}=0.16\right)$. This pattern was obtained because the FA rate remained stable for associative memory ( $P \mathrm{~s}>0.10)$, but increased for item memory from $1 \mathrm{~d}$ to $1 \mathrm{mo}$ $(P \mathrm{~s}<0.002)$ (Fig. 5B). In addition, the FA rate was significantly higher for item memory than for associative memory in 1-wk and 1-mo intervals (Ps $<0.03)$ but not in 10-min and 1-d intervals $(P s>0.30)$. RTs were longer for associative memory than item memory $\left(F_{(1,21)}=103.93, P<0.001, \eta^{2}=0.83\right)$. No significant interaction was found $\left(F_{(3,63)}=1.73, P=0.17, \eta^{2}=0.07\right)$.

Regarding the contribution of recollection, there was a significant interaction between time interval and memory type $\left(F_{(3,63)}=3.07, P<0.03, \eta^{2}=0.14\right)$. Similar to the results for corrected recognition, for associative memory, the recollection estimates decreased between $1 \mathrm{wk}$ and $1 \mathrm{mo}(P<0.001)$ but not from 10 min to $1 \mathrm{wk}(P \mathrm{~s}>0.10)$; for item memory, the recollection contribution decreased linearly from $10 \mathrm{~min}$ to $1 \mathrm{mo}(P \mathrm{~s}<0.01)$ (Fig. 5C). For the contribution of familiarity, there were no significant effects of retention interval, test, and their interaction $(F \mathrm{~s}<$ $2.0, P>0.20)$. The recollection contribution was greater than familiarity over the various retention intervals $(P<0.001)$ except for the 1 -mo interval $(P=0.19)$. The averaged guess response was $0.00 \pm 0.04$ after correction by the FA rate. They were not significantly higher than the chance level (0) for each condition $(P s>0.20)$. There were no significant effects of time and memory type, or significant interaction between them $(F \mathrm{~s}<2, P>0.15)$.

\section{Spacing effect (ML6 versus DL6)}

When ML6 and DL6 were compared, there were significant interactions between interval and group $\left(F_{(3,132)}=5.90, P<0.001\right.$, $\left.\eta^{2}=0.11\right)$ and between memory type and group $\left(F_{(1,44)}=4.11\right.$, $P=0.048, \eta^{2}=0.08$ ) for the corrected recognition. Compared with ML6, DL6 significantly increased memory at the 1-wk and 1-mo intervals $\left(P_{\mathrm{s}}<0.003\right)$ but not at the 10-min and 1-d intervals $(P s>0.50)$. In addition, associative memory performance was significantly higher in the DL6 than ML6 group $(P=0.012)$, but the learning mode did not influence item memory performance $(P=0.25)$. Distributed learning significantly increased the contribution of recollection $\left(F_{(1,44)}=7.52, P=0.009, \eta^{2}=0.14\right)$, but familiarity remained stable $\left(F_{(1,44)}=1.26, P=0.27, \eta^{2}=0.03\right)$. More importantly, the interaction between group and time interval was significant for recollection $\left(F_{(3,132)}=4.94, P=0.003, \eta^{2}=0.10\right)$, because recollection decreased more slowly at longer intervals in DL6 (versus ML6), and contributed more to for DL6 than ML6 at 1 -wk and 1-mo intervals. Thus, spacing significantly decreased the forgetting rate especially at longer intervals, the effect being dependent on the contribution of recollection.

We also compared the encoding difference between ML6 and DL6. Participants made judgment for sentence task (three times, yes/no) and vividness judgment for imagination task (three times, 1-5). Participants make high "yes" judgments during sentence task, and there were no significant differences in learning and group $(P \mathrm{~s}>0.5)$. The results showed that the vividness scores increased from first to the third time $(2.03 \pm 0.27 ; 2.07 \pm 0.36$; $2.12 \pm 0.37), F_{(2,112)}=8.15, P=0.001, \eta^{2}=0.13$. But group effect and interaction between learning time and group were not significant, $F \mathrm{~s}<1$. It suggested that learning increases encoding vividness for both ML6 and DL6.

\section{Learning effect (ML3 versus ML6)}

The corrected recognition increased after ML6 versus ML3 $\left(F_{(1,50)}=4.54, P=0.038, \eta^{2}=0.08\right)$. There was a marginally significant interaction between interval and learning $\left(F_{(3,150)}=\right.$ 2.26, $\left.P=0.083, \eta^{2}=0.04\right)$, because learning effect was apparent 
only for the 1-d interval ( $P=0.004)$, leading to slower forgetting from $10 \mathrm{~min}$ to $1 \mathrm{~d}$ for both item and associative memories. Recollection was greater for ML6 than ML3 $\left(F_{(1,50)}=4.00, P=\right.$ $\left.0.05, \eta^{2}=0.07\right)$, with significant interactions between interval and learning $\left(F_{(3,150)}=4.05, P=0.004, \eta^{2}=0.08\right)$, as the learning effect appeared at $1-\mathrm{d}$ and $1-w \mathrm{k}$ intervals $(P s<0.03)$. There were no significant differences in learning effect and group-related interactions for familiarity ( $F \mathrm{~s}<1, P>0.40)$. It suggested that learning six times (versus three times) per day benefits memory for 1-d interval and recollection contributed to this effect.

\section{Summary and comment}

The result of Experiment 3 showed that for corrected recognition, forgetting was equivalent for both memory types at ML6. By comparison, the forgetting rate was significantly slowed down for DL6 for associative memory by the contribution of recollection. Compared with ML6, DL6 significantly decreased the forgetting rate of associative (versus item) memory at longer intervals.

The interaction between memory type and retention interval for DL6 was obtained when the encoding task was controlled, and the initial memory performance for each type was matched. The participants used the same learning mode for associative memory and item memory for each specific retention interval. The comparable memory performance on the initial day excluded the possibility of inferior encoding (Cepeda et al. 2006) and enabled us to compare memory type and forgetting rate without an initial memory difference (Elliott et al. 2014).

For the effect of learning time (ML6 versus ML3), the interaction between interval and learning was marginally significant. There was slower forgetting from $10 \mathrm{~min}$ to $1 \mathrm{~d}$ for both item and associative memories, which was consistent with the result of ML3 versus once with smaller effect. However, ML6 significantly increased the recollection contribution at $1 \mathrm{~d}$ and $1 \mathrm{wk}$ but left familiarity stable (versus ML3). It suggested that once learned for certain repetitions, increasing learning sessions may not have much of an influence on the forgetting rate after 1-d interval, and may not increase the familiarity contribution.

\section{Discussion}

In this study, retention interval and degree of learning were manipulated to explore their effects on the forgetting rates of item and associative memories. We asked whether these factors influenced the forgetting rate of item and associative memories, and to what extent the forgetting rate was related to the contributions of recollection and familiarity over time. There were four main findings in our three experiments. First, item and associative memory overall were forgotten at similar rates when participants learned the stimuli once and up to six times with massed presentations. Second, with the passage of time, the recollection process declined quickly over time and familiarity process remains relatively stable. This pattern occurred across degrees of learning (i.e., in three experiments). Third, learning more times significantly decreased the forgetting rate especially at shorter intervals. Both recollection and familiarity contributed to the learning effect. Fourth, compared with massed learning, distributed learning (six times) especially benefited associative memory by increasing recollection, leading to slower forgetting at longer intervals. The results of the three experiments suggested that the decline of recollection process is the main cause of forgetting over time. Degree of learning and spacing effect influenced the forgetting process mainly due to their effect on recollection. This study clarified the effects of learning on memory forgetting, and highlighted the importance of recollection contribution in determining memory forgetting with the passage of time.

\section{Recollection, familiarity, and forgetting}

Across three experiments examining the effects of delay and massed and distributed learning on item and associative memory, the novel, overarching finding is that the forgetting rate of item and associative memories are determined primarily by the underlying recollection and familiarity processes. Recollection declined over time, whereas familiarity remained relatively stable for both item and associative memory irrespective of degree of learning. Because the pattern of recollection change was the same as that of corrected recognition, and familiarity process remained stable, it suggested that the decline of recollection component is the main cause of forgetting for both item and associative memories.

Our results are consistent with the hypothesis proposed by Sadeh et al. (2014) that with time, recollection-based memory is more likely to be forgotten than familiarity-based memory. Accordingly, memory loss should be greater for recollection at early stage, and then asymptote, which are what our data and data from other studies suggest. In addition, the decline of recollection occurred irrespective of the way the stimuli learned. After participants learned the words and word pairs three or six times, recollection increased significantly. The contribution of familiarity increased for learning three times versus once, too. Nevertheless, the forgetting pattern did not change for these two processes, consistent with the hypothesis of Sadeh et al. (2014).

We further found that when the study-test interval was longer than $1 \mathrm{wk}$, memory depends on the contribution of both processes (Gardiner and Java 1991; Tunney and Bezzina 2007). The unitized association could be formed and retrieved without conscious awareness (Quamme et al. 2007), thus it is possible that even in Experiment 1, the unitization occurs during encoding and supports the associative memory when the recollection process is not accessible (i.e., 1-mo intervals).

Previous studies have reached inconsistent conclusions about whether item and associative memories have similar forgetting rates over time when the material is learned once (e.g., Hockley and Consoli 1999; Talamini and Gorree 2012). Based on our results, we can surmise that these inconsistencies may be related to the nature of the underlying recollection and familiarity processes. Thus, some studies found differential change for recollection and familiarity over time after a single exposure (e.g., Gardiner and Java 1991; Hockley and Consoli 1999). In the present study, we further found that when the study-test interval was longer than $1 \mathrm{wk}$, memory depends on the contribution of both processes (Gardiner and Java 1991; Tunney and Bezzina 2007). On the one hand, the recollection contributed more to associative than to item memory, and decayed over time after learning once. On the other hand, familiarity contributed more to item than to associative memory, and did not change across time. Thus, in general, the difference in forgetting rate between item and associative memories was minimal. It is reasonable to assume that the extent to which recollection contributed to a certain memory type, in this case item and associative memory, is a better way to determine how quickly the memory is forgotten. For example, memory for object-object and object-position pairs may rely primarily on recollection because forming these associations needs detailed information, thus memory for these associations declines to a greater extent than memory for single objects (Talamini and Gorree 2012).

\section{Learning effect and forgetting}

One of the novel findings of the study was that learning modulated the forgetting rate in shorter intervals due to contributions of recollection and familiarity. First, both recollection and familiarity contributed to the learning effects for ML3 versus once. After 
learning multiple times, participants obtained more detailed information and more familiar experience of the words and word pairs, which may lead to increased recollection (Barber et al. 2008) and familiarity contributions (Kilb and Naveh-Benjamin 2011; Ahmad and Hockley 2014). On the other hand, familiarity process increased after ML3 versus once but not for ML6 versus ML3. It suggested that when stimuli are repeatedly learned, simply increasing the number of repetitions does not increase familiarity. Second, after learning multiple times, forgetting rate was decreased (or slowed down) at shorter intervals. Like other aspects of forgetting caused by delay, this effect was mainly driven by the recollection process, because the familiarity process did not change over time. Increasing recollection made participants forget fewer details over time, but the increased recollection mainly appeared in $1 \mathrm{~d}$ (and $1 \mathrm{wk}$ ), slowing down forgetting from 10 min to $1 \mathrm{~d}$ for both item and associative memories.

Previous studies have inconsistent findings on whether learning influence the forgetting rate. Some found participants forgot less when stimuli were learned multiple times (e.g., Ebbinghaus 1885/1964; Loftus 1985) but others did not (e.g., Slamecka and McElree 1983). In this study, we used the same analysis as Slamecka and McElree (1983), and the results were different from theirs. There are some differences in methods, which may influence the results. First, the comparison of time intervals was between participants in their study, and the recall and recognition used the same word pairs. As the recognition-matching task for word pairs followed cued recall, it is difficult to delineate the influence of recall on recognition performance. Second, Slamecka and McElree (1983) presented words auditorily and used a recall test. Because recall relies mainly on recollection, and we found that learning three times increased both recollection and familiarity, the difference between once and three times may not be significant.

The slower forgetting rate associated with multiple learning may be related to encoding and sleep-based consolidation processes. By presenting the stimuli three or six times, participants processed them repeatedly and hence had the opportunity to increase detailed and gist-like information, leading to increased recollection and familiarity. Because the delayed forgetting occurred between $10 \mathrm{~min}$ and $1 \mathrm{~d}$, sleep cycle seems important. Studies have suggested that during a normal sleep cycle, especially the sleep at the first night after learning (Sterpenich et al. 2009), new and initially labile memories can be transformed into more stable representations (Diekelmann and Born 2010). In addition, memory after several repetitions is more likely to be selected in sleep-based consolidation (Breton and Robertson 2014). Though speculative, it is possible that presleep learning experience influences subsequent consolidation and forgetting rate.

\section{Spacing effect (massed versus distributed learning) and forgetting}

The formation of a memory is highly sensitive not only to the total amount of training, but also to the pattern of trials used during training. We clarified how spacing modulated memory and the forgetting rate. Compared with massed learning, distributed learning (six times) especially benefited associative memory by increasing recollection, leading to slower forgetting at longer intervals. As we did not find a significant interaction between interval and group when participants learned three times (DL3 versus ML3) in Experiment 2, it is possible that learning twice a day is optimal for remote memory especially if it is associative.

The spacing effect has been found in many studies, showing higher memory performance for DL than ML (for review, see Cepeda et al. 2006). However, few studies have explored how spacing effect influence the forgetting rate of different types of mem- ories mediated by different processes. Like Litman and Davachi (2008), we found associative memory benefited from DL (versus $\mathrm{ML}$ ). Furthermore, our study clarified that spacing effect was manifested especially at longer study-test intervals. Compared with ML6, DL6 led to a decrease in forgetting from 1-wk interval in associative memory. Unlike Litman and Davachi's (2008) study, we did not find the significant difference between DL and ML for the 1-d interval; the difference between DL6 and ML6 appeared at the 1 -wk and 1-mo intervals. One difference between our study and theirs was that we manipulated the learning mode as a betweenparticipants factor, which excluded the influence of the two different sessions. In a within-participants design, ML lists are usually learned the second day, and thus, they are more susceptible to the interference from the DL list, which may have been consolidated during sleep.

The results supported our hypothesis that DL enhances memory for detailed information, and in turn enhances the contribution of recollection process. Because the forgetting rate is more related to the recollection process, DL leads to slower forgetting than ML. The reason for the spacing effect may be related to encoding variability (Glenberg 1979; Janiszewski et al. 2003; Cepeda et al. 2006) and reactivation process (Benjamin and Tullis 2010). DL6 may improve memory by increasing the probability of successful trace retrieval (Estes 1955; Glenberg 1979; Cepeda et al. 2006). Recent neuroimaging studies have suggested that spaced learning enhances recognition memory by reducing neural repetition suppression in cortical regions (Wagner et al. 2000; Xue et al. 2011), which could lead to enhanced encodingrelated neural activity upon repeated presentation (Wagner et al. 2000). It would be interesting to include more encoding parameters to evaluate whether reactivation influenced item and associative memories in a different way.

The reason that forgetting rate was slowed down for the distributed (versus massed) learning may be due to consolidation process involving the hippocampus. At the neural level, studies have shown that activity in the hippocampus is highly associated with recollection, which suggested that in the dimension of time, decrease of hippocampus activity leads to recollection decrease, and manifest forgetting in behavioral performance (Eichenbaum et al. 2007; Sadeh et al. 2014). DL increased the connectivity between the hippocampus and perirhinal cortex, which was correlated with decreased forgetting of associative memory (Vilberg and Davachi, 2013). Moreover, the two additional reactivations of the stimuli may trigger the reconsolidation processes via the hippocampus (Nader and Hardt 2009; Wang and Morris 2010), facilitate the process of assimilating new information into the old memory system (Nader and Hardt 2009) and strengthen existing memories (Sara 2000; Inda et al. 2011). These in turn increase recollection contribution and delay the forgetting.

Other studies have suggested that sleep-based consolidation is more important for associative memory than item memory (Cairney et al. 2011; van der Helm et al. 2011; Bell et al. 2014) because associative memory requires $24 \mathrm{~h}$ to consolidate whereas item memory requires less (Ellenbogen et al. 2007). Therefore, it is possible that DL especially enhances memory representation of associations between unrelated items. As associative memory takes a longer time to be consolidated, the spacing effect appears at longer time intervals.

\section{Distinction between item and associative memories}

One of the distinctions between item and associative memory is that associative memory mainly relies on the recollection process, whereas item memory relies on both recollection and familiarity processes (Davachi 2006; Cohn and Moscovitch 2007; Eichenbaum et al. 2007; but see Squire et al. 2007). We obtained 
similar results in our study. For associative memory, the contribution of recollection was greater than that of familiarity at 10-min and 1-d intervals after single learning, and extended to $1 \mathrm{wk}$ after multiple learning. For item memory, the recollection contribution was greater than that of familiarity at 10 min after single learning, and extended to $1 \mathrm{~d}$ after multiple learning. Our participants were asked to encode item and associative memories separately. This procedure may increase recollection in item memory, especially after multiple learning. The contribution of recollection and familiarity was comparable for item memory at 1 -wk and 1-mo intervals. In another way, associative memory had more recollection contribution than item memory especially at 10-min and 1-d intervals (learning once), and even $1 \mathrm{wk}$ (learning three times). In contrast, item memory had more familiarity contribution than associative memory at shorter intervals after learning three times. The findings were consistent with previous reports that associative memory is more dependent on recollection and item memory is more dependent on familiarity (Yonelinas and Levy 2002; Eichenbaum et al. 2007).

On the other hand, we should note that, both recollection and familiarity processes were involved in associative and item memories, though their degree of involvement differed. In other words, when participants remember a word or a word pair, they have to remember the details and contexts of the word or the relation between words. At the same time, they obtain familiarity or general knowledge of the stimuli. Both detailed and gist-like information help them retrieve the stimuli (Winocur and Moscovitch 2011). Our results showed that the forgetting rate associated with recollection remained consistent irrespective of learning experience, which highlighted the critical role of recollection contribution in memory forgetting. It suggested that it is the processes of recollection and familiarity, rather than the type of memory that determine the forgetting characteristics.

In comparison to the two(dual)-process model of recognition which we have applied so far, one-process models attribute the recognition change in different conditions (e.g., item versus associative memory) to memory strength (for review, see Eichenbaum et al. 2007; Squire et al. 2007). They assume that strong memory has unequal variances, thus participants may have higher confidence and higher performance for strong memory (versus weak memory), leading to higher "remember" response (Squire et al. 2007). Despite the assumptions and theoretical proposal, both types of models agree on the basic notion that item and associative memory may differ in some aspects. The current study was not designed to address the debate, or reconcile the two views, but the findings suggested that recollection/familiarity distinction is a more appropriate way to account for the data. According to strong/weak memory proposal, forgetting process is a change from strong to weak memory representation. If so, recollection contribution should decrease but familiarity increase. Contrary to the latter prediction, we found that over time the familiarity process remained relatively stable. In contrast, the distinction in recollection and familiarity explained well the current findings on forgetting, learning, and spacing effects. We, therefore, suggested that the recollection/familiarity distinction is a more appropriate way to explain the dissociation between item and associative memories over time.

There are some debates on whether Remember/Know procedure (Tulving 1985; Gardiner 1988) is a valid approach to assess recollection and familiarity processes (for review, see Donaldson 1996; Wixted and Stretch 2004). However, we should note that some studies have adopted both $\mathrm{R} / \mathrm{K}$ and ROC curves using the dual-process signal detection (Yonelinas and Levy 2002) procedures and obtained similar findings on various issues (e.g., Koen and Yonelinas 2010; Ozubko et al. 2012). Particularly, there are many studies using $\mathrm{R} / \mathrm{K}$ and ROC paradigms have found that the proportion of recollection greatly decreases over time (for review, see Sadeh et al. 2014). Wais et al. (2006) also used ROC curves and confirmed that recollection estimates decrease with time to a greater degree than familiarity estimates. These results suggested that when participants follow appropriate instructions, $\mathrm{R} / \mathrm{K}$ procedure could provide valid process measures that converge quite well with other measures.

\section{Conclusions}

In summary, our study showed that across different degrees of learning, the recollection process declines over time and familiarity process remains relatively stable. Repetition learning significantly slowed the forgetting rate at shorter intervals, and both recollection and familiarity contributed to the modulation. Compared with ML, DL specifically increase the recollection process especially at the longer intervals, with associative memory benefiting more from spacing effect than item memory, leading to slower forgetting rate. This study highlighted the importance of process contribution and learning experiences in modulating the forgetting rates of item and associative memories.

Whether associative memory is dissociated from item memory is a central issue of memory research (Murdock 1997). The memory models differ in their assumption of whether item memory and associative memory are independent (e.g., TODAM, Murdock 1997) or not (e.g., SAM, Gillund and Shiffrin 1984). The current study contributes to the current models in that it provides evidence on how item and associative memories change over time, and how they are influenced by degree of learning. More importantly, the results emphasized that the underlying differences in recollection and familiarity processes is a better way to account for the item and associative memory differences we observed with respect to learning and forgetting.

\section{Materials and Methods}

\section{Experiment 1}

\section{Participants}

Twenty-four healthy, right-handed participants (11 males) with a mean age of $21.38 \pm 2.06 \mathrm{yr}$ were recruited in the study. All of the participants were native Chinese speakers, and they all provided written informed consent in accordance with the procedures and protocols approved by the Review Board of Peking University.

\section{Material}

Two within-subjects factors were included in the study: memory type (associative, item) and retention interval (10 min, $1 \mathrm{~d}, 1$ wk, and $1 \mathrm{mo}$ ). We first selected 618 Chinese words that were all composed of two Chinese characters. These words were placed in 309 unrelated pairs (e.g., tooth-tree, window-air), and nine of them were used as practice pairs. The remaining 300 word pairs had moderate word frequency (18.04 \pm 32.15 per million) and moderate numbers of word strokes $(18.39 \pm 4.83)$. The word pairs were divided into five sets to be used for four retention intervals and as new stimuli (60 pairs per set). The words in the five sets had comparable word frequency and numbers of strokes $(P s>0.10)$. The two words in a pair had no relations in semantic, phonological, and orthographical features. We also rated the extent to which the word pairs were related, the ability to visualize them, the familiarity, and the concreteness of the words (five participants). The words in the five sets had comparable features $(P s>0.60)$. In addition, the words on the left and right side of the pairs had comparable features $(P s>0.10)$. The five sets were balanced using the Latin-square principle, so each set had an equal chance of being used for the four retention intervals and for the new set. 


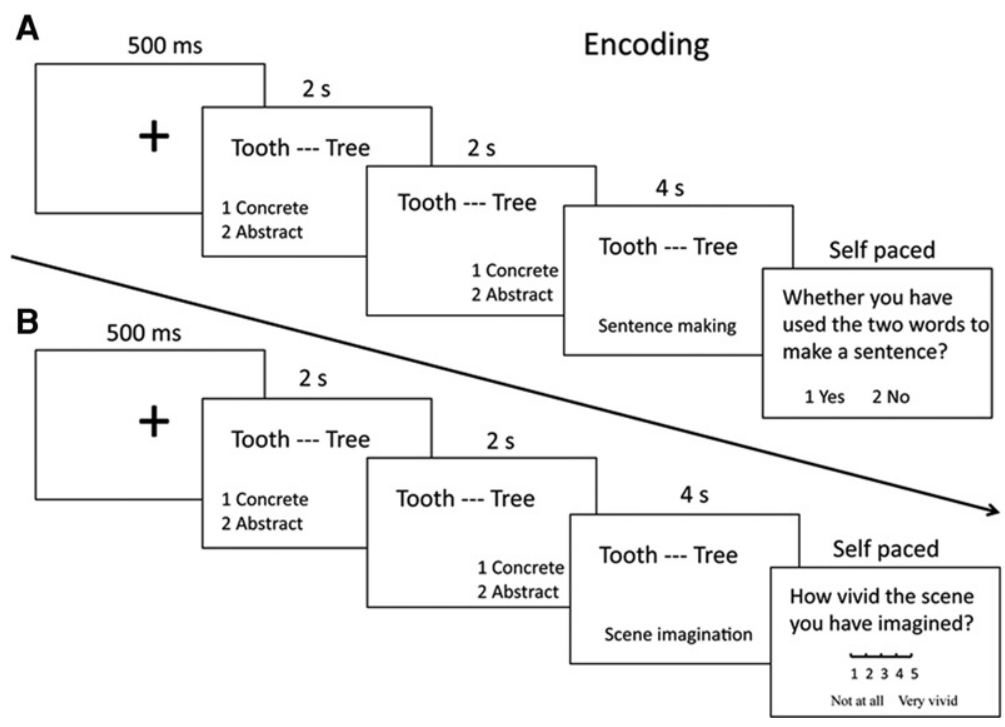

Figure 6. Procedure of the study phase. For each trial, participants first performed a concreteness judgment for each word, then performed a sentence-making task ( $A$, in Experiment 1-3) or an imagination task ( $B$, in Experiment 3). Chinese words are replaced by English words for illustration purpose.

For each set, the 60 pairs were divided into three subsets. Among them, 20 pairs were used as intact pairs in the test phase (e.g., tooth-tree), 20 pairs were used as recombined pairs (without changing the left/right position of the words, e.g., tooth-air), and the words in other 20 pairs were used as old (single) words in the test phase (half from the left and half from the right, e.g., window, tree). The new words were selected from the new set. Thus, word recognition and associative recognition used different material for each participant. The stimuli were counterbalanced so that each word and word pair had an equal chance to be used as old or new words and old or recombined pairs.

\section{Procedure}

During the study phase (Fig. 6A), for each trial, the word pair was presented on the center of the screen for $2 \mathrm{sec}$ while the participants first judged the concreteness of each of the two words from left to right separately. This ensured that participants encoded the words as well as the word pairs. Next, the word pair was presented again for $4 \mathrm{sec}$ while the participants were asked to form a sentence combining the unrelated words. Finally, to assess whether participants performed the task well, they judged how well they made a sentence to connect the two words on a scale of 1-3. All stimuli were pseudorandomly presented during the encoding phase so that no more than three stimuli that were tested in the same time interval were presented consecutively.

During the test phase, item and associative memory performance over different retention intervals was tested separately (i.e., 10-min, 1-d, 1-wk and 1-mo later after study). To test item memory, the old or new word was presented on the center of the screen for $2 \mathrm{sec}$, and the participants judged whether the word was old or new as accurately and quickly as possible (Fig. 7A). To test associative memory, the old or recombined word pairs were presented for 2

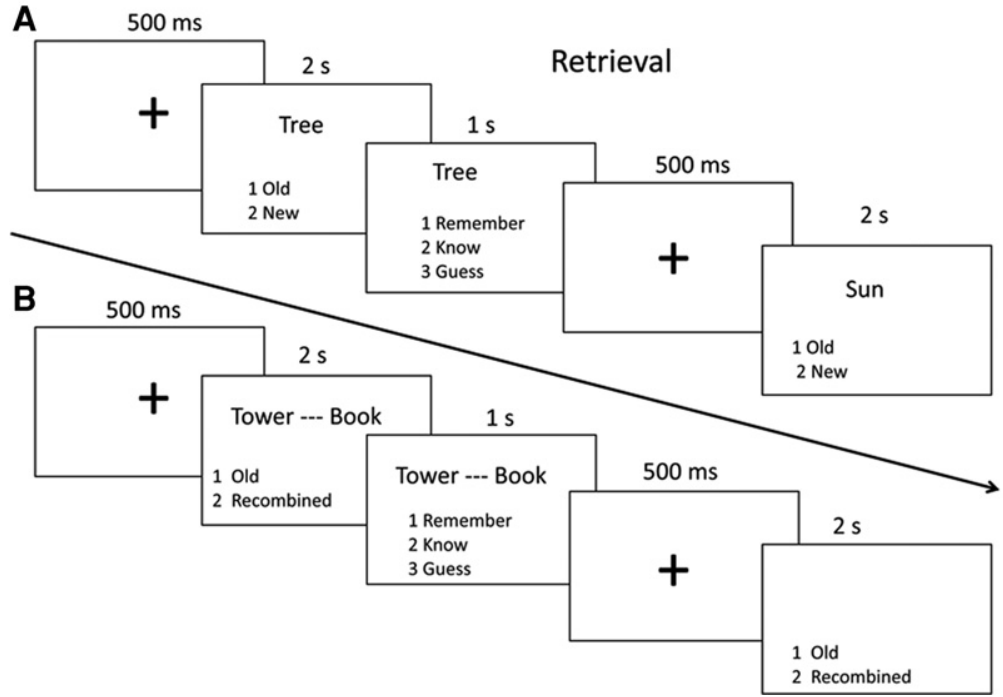

Figure 7. Procedure of the test phase. sec, and the participants judged whether the pair was old or recombined as accurately and quickly as possible (Fig. 7B). The word or word pair disappeared right after participants made the judgment. After the old/new judgment, the word or the word pair was again presented for $1 \mathrm{sec}$ and participants were asked to state whether they remembered or knew or guessed it. If participants judged that they could retrieve stimulus-related details or contexts, they responded as "remember"; if they only felt that the stimulus was familiar without any detailed information, they responded as "know." If they did not believe they retrieved the stimulus by the above two processes, they responded "guess." The old/new words and the old/recombined word pairs were presented randomly in each task, and the order of the two tasks was counterbalanced across participants.

Before each test phase, to avoid a rehearsal from the study phase, the participants were asked to count backward by seven continuously from 1000 for 5 min. In addition, to prevent the participants from rehearsing the stimuli after the study phase, they were reminded that it was not necessary to intentionally retrieve or forget the stimuli. The participants had separate opportunities to practice study and test trials before the formal phase.

\section{Data analysis}

The hit rate, false alarm rate (FA), corrected recognition (Hit-FA), and the mean RTs were calculated and analyzed separately using a repeated-measures ANOVA with the time interval $(10 \mathrm{~min}, 1 \mathrm{~d}$, $1 \mathrm{wk}, 1 \mathrm{mo}$ ) and the memory type (item, associative) as withinsubjects factors. The RTs was based on the mean RTs and only correct responses were included in the analysis. We excluded the participants if their Hit rates at the 20-min interval were at the chance level, or the Hit-FA rate at the 20-min interval were lower than the mean $(>2 \mathrm{SD})$. One subject's data were excluded due to low Hit rate at 20 -min interval. The forgetting rate was estimated by the interaction between the retention interval and the memory 
type (Slamecka 1985; Gardiner and Java 1991) based on previous studies (e.g., Gardiner and Java 1991; Hockly and Consoli 1999; Elliott et al. 2014). Partial Eta Squared $\left(\eta^{2}\right)$ was calculated to estimate the effect size of each analysis. Post hoc pairwise comparisons were Bonferroni-corrected. The $d^{\prime}$ was also calculated for each subject and averaged according to signal detection theory. Because the results of $d^{\prime}$ value and corrected recognition were similar, only the corrected recognition results are reported in detail.

Recollection and familiarity processes were estimated using the independent K (IRK) procedure (Yonelinas and Jacoby 1995; Yonelinas and Levy 2002), in which R responses are assumed to estimate recollection whereas familiarity is estimated as the proportion of $\mathrm{K}$ responses divided by the proportion of non- $\mathrm{R}$ responses. By this, the $\mathrm{R}$ and $\mathrm{K}$ responses are not only mutually exclusive, but also independently estimated. Then R and IRK responses were then corrected using the FA: Recollection $=P(\mathrm{R}$, Hit $)-P(\mathrm{R}, \mathrm{FA})$; Familiarity $=P(\mathrm{~K}$, Hit $) /(1-P(\mathrm{R}$, Hit $))-P(\mathrm{~K}, \mathrm{FA}) /$ $(1-P(\mathrm{R}, \mathrm{FA}))$. Repeated-measures ANOVA tests were performed separately for recollection and familiarity processes with the retention interval and the memory type as within-subjects factors.

\section{Experiment 2}

\section{Participants}

Fifty-seven healthy, right-handed participants (18 males) with a mean age of $22.03 \pm 2.40 \mathrm{yr}$ were recruited in the experiment. Among them, 29 participants were randomly assigned to ML group ( 8 male, $21.18 \pm 2.50 \mathrm{yr}$ ), and 28 participants were assigned to DL group (10 male, $21.03 \pm 1.80 \mathrm{yr})$. No age and gender difference were found between groups $(P s>0.9)$. All of the participants were native Chinese speakers, and they all gave written informed consent in accordance with the procedures and protocols approved by the Review Board of Peking University.

\section{Procedure and data analysis}

Two within-subjects factors and one between-subjects factor were included in Experiment 2: memory type (associative, item), time interval (10 min, $1 \mathrm{~d}, 1 \mathrm{wk}$, and $1 \mathrm{mo}$ ), and group (ML, DL). The stimuli were the same as those used in Experiment 1. The procedure was the same as that in Experiment 1, except the following: (1) each word pair was presented three times in three sessions within a day for the ML group (i.e., ML3). For each learning session, all stimuli were pseudorandomly presented once so that no more than three stimuli in the same time intervals were continuously presented. (2) Each word pair was presented three times in $3 \mathrm{~d}$ for the DL group (once per day, i.e., DL3). Different random orders were used for each learning session. As in Experiment 1, the 10-min stimuli were tested after all study sessions were completed.

Data analysis was performed in the same manner as in Experiment 1. The data of one participant in ML3 group and four participants in DL3 group were excluded due to low memory performance (Hit rate or Hit-FA rate) or failure to follow the instructions. In addition, to compare the spacing effect on the forgetting rate, an additional ANOVA was performed with group (ML3 versus DL3) as a between-subjects factor. To compare the effect of learning time on the forgetting rate, another ANOVA was performed with learning (once versus ML3) as a between-subjects factor.

\section{Experiment 3}

\section{Participants}

Forty-seven right-handed participants ( 22 males) with a mean age of $21.59 \pm 2.50 \mathrm{yr}$ were recruited in the study. Among them, 24 participants were randomly assigned to ML group (8 males, $21.46 \pm 2.16 \mathrm{yr}$ ), and 23 participants were assigned to DL group (14 male, $21.55 \pm 2.76 \mathrm{yr}$ ). No age and gender difference were found between groups $(P \mathrm{~s}>0.9)$. All of the participants were native Chinese speakers, and they all gave written informed consent in accordance with the procedures and protocols approved by the Review Board of Peking University.

\section{Procedure and data analysis}

Two within-subjects factors and one between-subjects factor were included in Experiment 3: memory type (associative, item), time interval (10 min, $1 \mathrm{~d}, 1 \mathrm{wk}$, and $1 \mathrm{mo}$ ) and group (ML6, DL6). The stimuli were the same as those used in Experiment 1 . The procedure was the same as that in Experiment 2, except the following: (1) each word pair was presented six times within a day for the ML group (ML6), and each word pair was presented six times in $3 \mathrm{~d}$ for the DL group (twice per day, DL6). (2) Participants were asked to form a sentence or an imagination combining the unrelated words alternately during encoding (Fig. 6B), and to assess whether subjects performed the task well, they judged the success of their sentence or their imagination to connect the two words. The order of the two tasks was counterbalanced across the participants. The stimuli were pseudorandomly presented during each session. The data analysis was performed in the same manner as in Experiment 2. Again, we compared the data of ML6 and DL6 to be the index of spacing effect, and data of ML3 and ML6 to be the index of learning effect.

\section{Acknowledgments}

This research was supported by the grant from the National Science Foundation of China $(31171078,31571114$, J.Y.). The funder had no role in study design, data collection, and analysis, decision to publish, or preparation of the manuscript. We thank Dr. Talya Sadeh from University of Toronto for her valuable suggestions on the earlier draft of the manuscript.

\section{References}

Ahmad FN, Hockley WE. 2014. The role of familiarity in associative recognition of unitized compound word pairs. Q J Exp Psychol 67: 2301-2324.

Barber SJ, Rajaram S, Marsh EJ. 2008. Fact learning: how information accuracy, delay, and repeated testing change retention and retrieval experience. Memory 16: 934-946.

Bell MC, Kawadri N, Simone PM, Wiseheart M. 2014. Long-term memory, sleep, and the spacing effect. Memory 22: 276-283.

Benjamin AS, Tullis J. 2010. What makes distributed practice effective? Cogn Psychol 61: 228-247.

Bogartz RS. 1990. Evaluating forgetting curves psychologically. J Exp Psychol Learn Mem Cogn 16: 138-148.

Bornstein BH, LeCompte DC. 1995. A comparison of item and source forgetting. Psychon Bull Rev 2: 254-259.

Bowles B, Crupi C, Mirsattari SM, Pigott SE, Parrent AG, Pruessner JC, Yonelinas AP, Kohler S. 2007. Impaired familiarity with preserved recollection after anterior temporal-lobe resection that spares the hippocampus. Proc Natl Acad Sci 104: 16382-16387.

Breton J, Robertson EM. 2014. Flipping the switch: mechanisms that regulate memory consolidation. Trends Cogn Sci 18: 629-634.

Brown AS, Halliday HE. 1991. Cryptomnesia and source memory difficulties. Am J Psychol 104: 475-490.

Brubaker MS, Naveh-Benjamin M. 2014. The effects of presentation rate and retention interval on memory for items and associations in younger adults: a simulation of older adults' associative memory deficit. Neuropsychol Dev Cogn B Aging Neuropsychol Cogn 21: 1-26.

Cairney SA, Durrant SJ, Musgrove H, Lewis PA. 2011. Sleep and environmental context: interactive effects for memory. Exp Brain Res 214: $83-92$.

Cepeda NJ, Pashler H, Vul E, Wixted JT, Rohrer D. 2006. Distributed practice in verbal recall tasks: a review and quantitative synthesis. Psychol Bull 132: $354-380$.

Cohn M, Moscovitch M. 2007. Dissociating measures of associative memory: evidence and theoretical implications. J Mem Lang 57: $437-454$.

Davachi L. 2006. Item, context and relational episodic encoding in humans. Curr Opin Neurobiol 16: 693-700.

Diekelmann S, Born J. 2010. Sleep: the memory function of sleep. Nat Rev Neurosci 11: 114-126.

Donaldson W. 1996. The role of decision processes in remembering and knowing. Mem Cogn 24: 523-533. 
Ebbinghaus EE. 1964. Memory (H A Ruger and CE Bussenius, Trans.). Dover. New York. (Original work published 1885).

Eichenbaum H, Yonelinas AP, Ranganath C. 2007. The medial temporal lobe and recognition memory. Annu Rev Neurosci 30: 123-152.

Ellenbogen JM, Hu PT, Payne JD, Titone D, Walker MP. 2007. Human relational memory requires time and sleep. Proc Natl Acad Sci 104: $7723-7728$.

Elliott G, Isaac CL, Muhlert N. 2014. Measuring forgetting: a critical review of accelerated long-term forgetting studies. Cortex 54: 16-32.

Estes WK. 1955. Statistical theory of distributional phenomena in learning. Psychol Rev 62: 369-377.

Gardiner JM. 1988. Functional-aspects of recollective experience. Mem Cogn 16: 309-313.

Gardiner JM, Java RI. 1991. Forgetting in recognition memory with and without recollective experience. Mem Cogn 19: 617-623.

Gardiner JM, Ramponi C, Richardson-Klavehn A. 2002. Recognition memory and decision processes: a meta-analysis of remember, know, and guess responses. Memory 10: 83-98.

Gilboa A, Winocur G, Grady CL, Hevenor SJ, Moscovitch M. 2004. Remembering our past: functional neuroanatomy of recollection of recent and very remote personal events. Cereb Cortex 14: 1214-1225.

Gillund G, Shiffrin RM. 1984. A retrieval model for both recognition and recall. Psychol Rev 91: 1-67.

Glenberg AM. 1979. Component-levels theory of the effects of spacing of repetitions on recall and recognition. Mem $\operatorname{Cogn}$ 7: 95-112.

Harand C, Bertran F, La Joie R, Landeau B, Mezenge F, Desgranges B, Peigneux P, Eustache F, Rauchs G. 2012. The hippocampus remains activated over the long term for the retrieval of truly episodic memories. PLoS One 7: e43495.

Hardt O, Nader K, Nadel L. 2013. Decay happens: the role of active forgetting in memory. Trends Cogn Sci 17: 111-120.

Hockley WE, Consoli A. 1999. Familiarity and recollection in item and associative recognition. Mem Cogn 27: 657-664.

Inda MC, Muravieva EV, Alberini CM. 2011. Memory retrieval and the passage of time: from reconsolidation and strengthening to extinction. J Neurosci 31: 1635-1643.

Janiszewski C, Noel H, Sawyer AG. 2003. A meta-analysis of the spacing effect in verbal learning: implications for research on advertising repetition and consumer memory. J Consum Res 30: 138-149.

Kilb A, Naveh-Benjamin M. 2011. The effects of pure pair repetition on younger and older adults' associative memory. J Exp Psychol Learn Mem Cogn 37: 706-719.

Knowlton BJ, Squire LR. 1995. Remembering and knowing - 2 different expressions of declarative memory. J Exp Psychol Learn Mem Cogn 21: 699-710.

Koen JD, Yonelinas AP. 2010. Memory variability is due to the contribution of recollection and familiarity, not to encoding variability. J Exp Psychol Learn Mem Cogn 36: 1536-1542.

Litman L, Davachi L. 2008. Distributed learning enhances relational memory consolidation. Learn Mem 15: 711-716.

Loftus GR. 1985. Evaluating forgetting curves. J Exp Psychol Learn Mem Cogn 11: $397-406$.

Mayes A, Montaldi D, Migo E. 2007. Associative memory and the medial temporal lobes. Trends Cogn Sci 11: 126-135.

Moscovitch M, Nadel L, Winocur G, Gilboa A, Rosenbaum RS. 2006. The cognitive neuroscience of remote episodic, semantic and spatial memory. Curr Opin Neurobiol 16: 179-190.

Murdock BB. 1997. Context and mediators in a theory of distributed associative memory (TODAM2). Psychol Rev 104: 839-862.

Nader K, Hardt O. 2009. A single standard for memory: the case for reconsolidation. Nat Rev Neurosci 10: 224-234.

Nilsson LG, Cohen RL, Nyberg L. 1989. Recall of enacted and nonenacted instructions compared-forgetting functions. Psychol Res Psychol Forsch 51: $188-193$.

Ozubko JD, Gopie N, MacLeod CM. 2012. Production benefits both recollection and familiarity. Mem Cogn 40: 326-338.

Quamme JR, Yonelinas AP, Normani KA. 2007. Effect of unitization on associative recognition in amnesia. Hippocampus 17: 192-200.

Sadeh T, Ozubko JD, Winocur G, Moscovitch M. 2014. How we forget may depend on how we remember. Trends Cogn Sci 18: 26-36.

Sadeh T, Ozubko JD, Winocur G, Moscovitch M. 2016. Forgetting patterns differentiate between two forms of memory. Psychol Sci, doi:10.1177/ 0956797616638307.

Sara SJ. 2000. Retrieval and reconsolidation: toward a neurobiology of remembering. Learn Mem 7: 73-84.
Sharot T, Yonelinas AP. 2008. Differential time-dependent effects of emotion on recollective experience and memory for contextual information. Cognition 106: 538-547.

Slamecka NJ. 1985. On comparing rates of forgetting-comment. J Exp Psychol Learn Mem Cogn 11: 812-816.

Slamecka NJ, McElree B. 1983. Normal forgetting of verbal lists as a function of their degree of learning. J Exp Psychol Learn Mem Cogn 9: 384-397.

Smith CN, Wixted JT, Squire LR. 2011. The hippocampus supports both recollection and familiarity when memories are strong. J Neurosci 31: 15693-15702.

Squire LR, Bayley PJ. 2007. The neuroscience of remote memory. Curr Opin Neurobiol 17: 185-196.

Squire LR, Wixted JT. 2011. The Cognitive neuroscience of human memory since HM. In Annual review of neuroscience (ed. Hyman SE, Jessell TM, Shatz CJ, Stevens CF, Zoghbi HY), Vol. 34, pp. 259-288.

Squire LR, Stark CEL, Clark RE. 2004. The medial temporal lobe. Annu Rev Neurosci 27: 279-306.

Squire LR, Wixted JT, Clark RE. 2007. Recognition memory and the medial temporal lobe: a new perspective. Nat Rev Neurosci 8: 872-883.

Sterpenich V, Albouy G, Darsaud A, Schmidt C, Vandewalle G, Vu TTD, Desseilles M, Phillips C, Degueldre C, Balteau E, et al. 2009. Sleep promotes the peural reorganization of remote emotional memory. J Neurosci 29: $5143-5152$.

Takashima A, Nieuwenhuis ILC, Rijpkema M, Petersson KM, Jensen O, Fernandez G. 2007. Memory trace stabilization leads to large-scale changes in the retrieval network: a functional MRI study on associative memory. Learn Mem 14: 472-479.

Talamini LM, Gorree E. 2012. Aging memories: differential decay of episodic memory components. Learn Mem 19: 239-246.

Tulving E. 1985. Ebbinghaus memory - what did he learn and remember. J Exp Psychol Learn Mem Cogn 11: 485-490.

Tunney RJ. 2010. Do changes in the subjective experience of recognition over time suggest independent processes? Br J Math Stat Psychol 63: $43-62$.

Tunney RJ, Bezzina G. 2007. Effects of retention intervals on receiver operating characteristics in artificial grammar learning. Acta Psychol (Amst) 125: 37-50.

van der Helm E, Gujar N, Nishida M, Walker MP. 2011. Sleep-dependent facilitation of episodic memory details. PLoS One 6: e27421.

Vilberg KL, Davachi L. 2013. Perirhinal-hippocampal connectivity during reactivation is a marker for object-based memory consolidation. Neuron 79: $1232-1242$.

Viskontas IV, Carr VA, Engel SA, Knowlton BJ. 2009. The neural correlates of recollection: hippocampal activation declines as episodic memory fades. Hippocampus 19: 265-272.

Wagner AD, Koutstaal W, Maril A, Schacter DL, Buckner RL. 2000. Task-specific repetition priming in left inferior prefrontal cortex. Cereb Cortex 10: $1176-1184$.

Wais PE, Wixted JT, Hopkins RO, Squire LR. 2006. The hippocampus supports both the recollection and the familiarity components of recognition memory. Neuron 49: 459-466.

Wang SH, Morris RGM. 2010. Hippocampal-neocortical interactions in memory formation, consolidation, and reconsolidation. Anпи Rev Psychol 61: 49-79.

Winocur G, Moscovitch M. 2011. Memory transformation and systems consolidation. J Int Neuropsychol Soc 17: 766-780.

Wixted JT. 1990. Analyzing the empirical course of forgetting. J Exp Psychol Learn Mem Cogn 16: 927-935.

Wixted JT, Stretch V. 2004. In defense of the signal detection interpretation of remember/know judgments. Psychon Bull Rev 11: 616-641.

Xue G, Mei L, Chen C, Lu Z-L, Poldrack R, Dong Q. 2011. Spaced learning enhances subsequent recognition memory by reducing neural repetition suppression. J Cogn Neurosci 23: 1624-1633.

Yonelinas AP, Jacoby LL. 1995. The relation between remembering and knowing as bases for recognition-effects of size congruency. J Mem Lang 34: 622-643.

Yonelinas AP, Levy BJ. 2002. Dissociating familiarity from recollection in human recognition memory: different rates of forgetting over short retention intervals. Psychon Bull Rev 9: 575-582.

Received November 25, 2015; accepted in revised form April 22, 2016. 


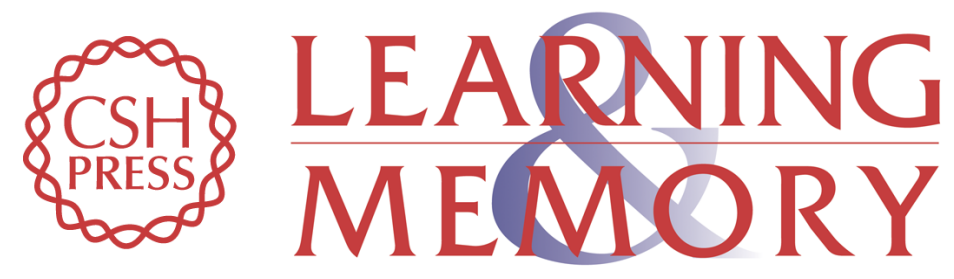

\section{Effects of learning experience on forgetting rates of item and associative memories}

Jiongjiong Yang, Lexia Zhan, Yingying Wang, et al.

Learn. Mem. 2016, 23:

Access the most recent version at doi:10.1101/Im.041210.115

References This article cites 72 articles, 9 of which can be accessed free at:

http://learnmem.cshlp.org/content/23/7/365. full.html\#ref-list-1

Creative This article is distributed exclusively by Cold Spring Harbor Laboratory Press for the

Commons

first 12 months after the full-issue publication date (see

License http://learnmem.cshlp.org/site/misc/terms.xhtml). After 12 months, it is available under a Creative Commons License (Attribution-NonCommercial 4.0 International), as described at http://creativecommons.org/licenses/by-nc/4.0/.

Email Alerting Receive free email alerts when new articles cite this article - sign up in the box at the Service top right corner of the article or click here. 